\title{
Coagulopathy in Cushing's Syndrome
}

\author{
Laura Trementino $^{\mathrm{a}}$ Giorgio Arnaldi $^{\mathrm{a}}$ Gloria Appolloni ${ }^{\mathrm{a}}$ Viviana Daidone ${ }^{\mathrm{b}}$ \\ Carla Scaroni $^{c}$ Alessandra Casonato $^{b}$ Marco Boscaro $^{a}$ \\ a Division of Endocrinology, Department of Internal Medicine, Polytechnic University of Marche Region, Ancona, \\ ${ }^{b}$ Department of Cardiac, Thoracic and Vascular Sciences, Second Chair of Internal Medicine, and 'Endocrinology \\ Unit, Department of Medical and Surgical Sciences, University of Padua, Padua, Italy
}

\section{Key Words}

Von Willebrand factor · Cushing's syndrome •

Hypercoagulable state $\cdot$ Cardiovascular risk .

Hypercortisolism

\begin{abstract}
A hypercoagulable state and its consequent increased incidence of thromboembolic complications are reported in patients with Cushing's syndrome (CS). These alterations are related to cortisol excess that induces prothrombotic changes in blood by several and complex mechanisms including increased levels of clotting factors, mainly factor VIII and von Willebrand factor (VWF) and impaired fibrinolytic capacity. However, it has recently been observed that the increase in VWF levels is not a constant feature of CS and that VWF response to glucocorticoids is genetically determined and depends on the presence of particular polymorphisms in the VWF gene promoter. The risk of venous thromboembolism is moreover enhanced in patients with CS by additional endogenous and exogenous risk factors such as obesity, bed rest, surgery and invasive diagnostic procedures like inferior petrosal sinus (IPS) sampling. In line with all these data, patients with active $\mathrm{CS}$ should be treated as having a prothrombotic disorder and undergo antithrombotic prophylaxis during IPS sampling. Special care should be taken in the im-
\end{abstract}

mediate perioperative period in order to avoid thromboembolic events. In the absence of prospective randomized trials, preventive antithrombotic treatment (best with heparin) during IPS sampling and low-dose heparin treatment early after surgery should be suggested.

Copyright $\odot 2010$ S. Karger AG, Basel

\section{Introduction}

In 1950, Cosgriff et al. [1] described increased coagulability in patients receiving glucocorticoids. Today, it is well known that glucocorticoid-induced hypercoagulability is common in patients with Cushing's syndrome (CS) representing, together with hypertension, impaired glucose metabolism, central obesity and hyperlipidemia, an important cardiovascular risk factor. For these clinical and biochemical manifestations, $\mathrm{CS}$ is associated with an increased cardiovascular mortality and morbidity [2-4].

The hypercoagulable state seen in these patients and the consequent increased incidence of thromboembolic complications are related to cortisol excess that induces prothrombotic changes in blood by several and complex mechanisms including quantitative and qualitative alteration in the hemostatic system (fig. 1). More recently, it has also been observed that in patients with CS the pres-

\section{KARGER}

Fax +41613061234

E-Mail karger@karger.ch

www.karger.com
(C) 2010 S. Karger AG, Basel

0028-3835/10/0925-0055\$26.00/0

Accessible online at:

www.karger.com/nen
Marco Boscaro

Clinica di Endocrinologia

Azienda Ospedaliero-Universitaria, Ospedali Riuniti di Ancona

IT-60100 Ancona (Italy)

Tel. +39071 88 7061, Fax +39071 88 7300, E-Mail m.boscaro@ univpm.it 


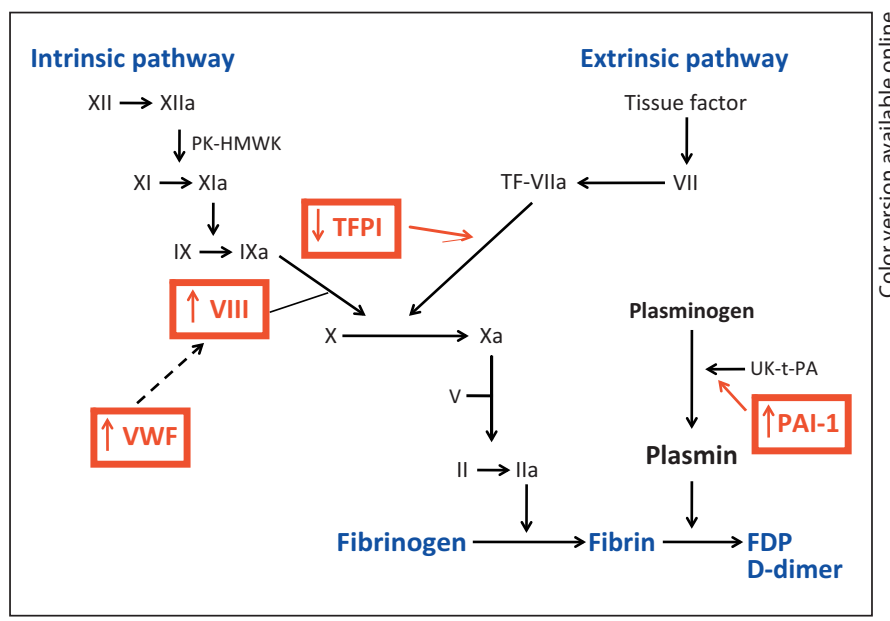

Fig. 1. Main prothrombotic alterations of clotting profile in CS. TFPI $=$ Tissue factor pathway inhibitor.

ence of particular polymorphisms in the von Willebrand factor (VWF) gene promoter plays a role in determining thrombotic risk.

Finally, additional endogenous (e.g. hyperhomocysteinemia, obesity) and exogenous (e.g. bed rest, surgery, invasive diagnostic procedures) factors may contribute and enhance the thromboembolic risk of patients with hypercortisolism.

In this short review, we discuss coagulation alterations in CS focusing on our personal experience and on mechanisms by which glucocorticoids may influence hemostatic parameters.

\section{Quantitative Alterations: Increased Clotting Factors and Impaired Fibrinolysis}

Whereas little is known about the effect of cortisol on platelet count and function, it is certain that the hypercoagulable state in CS is related to an increase in plasma clotting factors, especially factor VIII and VWF and, to a minor extent, to a defective fibrinolysis (fig. 1). In addition to plasma VWF and factor VIII, some studies have shown higher levels of other coagulation factors such as factors IX, XI, and XII [5-16].

We demonstrated that both increased clotting factors and defective fibrinolytic potential are related to the increased concentration of cortisol in the blood. High levels of glucocorticoids stimulate the endothelial production of VWF with a concomitant increase of factor VIII, which is transported in blood by the VWF, and impairs fibrinolytic capacity upregulating the synthesis of plasminogen activator inhibitor type 1 (PAI-1) [9-14].

In 1982, Dal Bo Zanon et al. [11] showed that active CS is associated with increased levels of factor VIII. They investigated 13 women and 2 men affected by CS every 30 50 days after treatment for 11 months: in these patients, circulating cortisol and factor VIII were significantly increased before treatment and decreased slowly after treatment to become normal in 3-4 months. The increase in VWF correlated well with cortisol levels.

In 1999, we studied the clotting profile in 20 patients with CS before and after surgical treatment [12]. In line with previous studies, plasma levels of factor VIII and VWF were markedly increased in these patients before surgery. In cured patients, an additional and significant increase during the first month after surgery was followed by a progressive decrease until a complete normalization within 12 months. This study confirmed the presence of quantitative alterations in clotting profile due to cortisol excess and their reversibility after the resolution of hypercortisolism, and identified a period of additional thrombotic risk early after surgery as a result of the worsening of the hemostatic pattern, exposing patients to a further and higher risk of thromboembolic complications.

The fibrinolytic system also plays a key role in the pathogenesis of venous thromboembolic disorders, and in patients with CS an impaired fibrinolytic capacity was described [13], mainly due to a decrease in tissue plasminogen activator (t-PA) antigen and increase in PAI-1. However, a case-control study did not find any significant difference in plasma PAI-1 and t-PA levels between CS patients and controls [14].

More recently, Erem et al. [15] reported increased levels of PAI-1 in CS patients compared with healthy subjects and decreased levels of the tissue factor pathway inhibitor that contributes to the hypofibrinolytic state of these patients and consequently to their increased thromboembolic risk. In this study, PAI-1 was also found to be positively correlated with midnight serum cortisol levels, a finding that emphasizes the strict relationship between these alterations and cortisol excess.

A shortening of the activated thromboplastin time was observed in our and in the majority of published clinical studies, whereas other coagulation parameters (prothrombin time, bleeding time, and platelet aggregation) were unchanged. A significant inverse correlation between activated thromboplastin time and urinary free cortisol levels was also observed [16]. 
The normal range of VWF levels is extremely wide since VWF concentrations may be modulated by several genetic and environmental factors, mainly $\mathrm{ABO}$ blood group, with O blood group individuals having $25 \%$ lower VWF levels than those with the other blood groups. This explains why CS patients may present different VWF concentrations, with no strict correlation with cortisol concentrations. Adjusting VWF levels to the ABO blood group, we recently demonstrated that the increase in VWF levels is not a constant feature of CS, since some patients may have normal VWF levels in spite of high circulating cortisol levels. Such variable VWF responses to the glucocorticoid action depend on particular polymorphisms in the VWF gene promoter: SNPs $-3268 \mathrm{G} / \mathrm{C}$, $-2709 \mathrm{C} / \mathrm{T}, 2661 \mathrm{~A} / \mathrm{G},-2527 \mathrm{G} / \mathrm{A}$ and the variable-lenght (GT)n locus. In CS, the presence of haplotype 1 (-3268G/ $-2709 \mathrm{C} /-2661 \mathrm{~A} /-2527 \mathrm{G})$ and short GT repeats (15-19 GT) was found to increase the risk of developing high VWF and, consequently, a hypercoagulable condition, while haplotype $2(-3268 \mathrm{C} /-2709 \mathrm{~T} /-2661 \mathrm{G} /-2527 \mathrm{~A})$ and long GT repeats ( $\geq 20 \mathrm{GT}$ ) correlated with normal VWF, thus representing a protective genetic element [17-19]. In CS, haplotype 1 and (GT)s alleles predict the increase in VWF, thus representing novel markers of thrombotic risk [17-19]. These and other inherited determinants may interact with hypercortisolism to increase the risk of thrombosis in a complex system. The knowledge of the genetic pattern of VWF promoter allows to define the thrombotic risk of these patients and their need for antithrombotic prophylaxis.

\section{Qualitative Alterations: Abnormalities in VWF Structure}

Hypercortisolism may also affect the multimeric structure of VWF causing an overexpression of abnormally high molecular weight multimers, capable of inducing spontaneous platelet aggregation [12].

VWF is a high molecular weight glycoprotein, synthesized and stored by both endothelial cells and megakaryocytes. VWF is organized as a polymeric molecule and plays a major role in primary hemostasis by promoting platelet adhesion to the subendothelium of the vessel wall. High molecular weight forms are known to have an increased hemostatic capacity [20].

In 1999, Casonato et al. [12] observed in 20 patients with CS not only higher plasmatic levels of VWF but also the presence of unusually large VWF multimers, normally not present in the plasma but only in the cellular com- partments where VWF is synthesized. CS patients thus appear characterized by an increase in a VWF molecule that is also hemostatically more efficient. This altered molecular organization of plasma VWF persisted after dilution of plasma to normalize VWF levels, suggesting that the phenomenon is independent of the increased VWF levels seen in CS patients and contributes per se to the hypercoagulable state of these patients. After therapeutic surgery, similar to that described for VWF plasma levels, in the immediate postoperative period a worsening in plasma VWF large multimer representation was observed followed by a subsequent gradual decrease in these alterations starting from the 3rd month after surgery. The incomplete disappearance of abnormally large VWF multimers, sporadically observed in cured patients, seems to indicate some persistence of the abnormal function of endothelial cells.

\section{Clinical Thromboembolic Complications and Additional Thrombotic Risk Factors}

Patients with CS are at high risk for venous thromboembolism (VTE), as demonstrated by Van Zaane et al. [7] in a recent systematic review on the effect of endogenous hypercortisolism on coagulation and fibrinolysis, as well as on the clinical outcome of VTE.

The risk of VTE is enhanced by additional endogenous and exogenous risk factors such as obesity, bed rest, surgery and invasive diagnostic procedures like inferior petrosal sinus (IPS) sampling [1, 6, 7, 21, 22].

Van Zaane et al. [7] observed, by data extraction from eight studies, a risk of 1.9 and $2.5 \%$ for VTE not provoked by surgery, with an estimated incidence rate of $2.5-$ $3.1 / 1,000$ persons/year versus $1-2 / 1,000$ in the normal population, whereas the risk of postoperative VTE varied between 0 and $5.6 \%$, with one outlier of $20 \%$. When compared with VTE rates after major orthopedic surgery (1.3-4.4\%), neurosurgery (0.5-2.3\%), gastrointestinal surgery $(0.2-1.6 \%)$, or urological surgery $(0.3-1.0 \%)$, the risk reported in patients with CS is remarkable [7].

There is currently a general agreement that antithrombotic prophylaxis should be routinely used in patients with Cushing's disease, especially when additional thrombotic risk factors such as surgery or invasive diagnostic procedures are present $[1,7,23,24]$.

Interesting results have emerged from our retrospective study on the use of anticoagulant prophylaxis with heparin and/or warfarin in a large series of patients with CS. The rates of thromboembolic events and related mor- 
tality were analyzed in 75 untreated (group 1) and in 232 treated (group 2) patients. Survival analysis demonstrated a significantly higher rate of thromboembolic events in group 1, not receiving anticoagulants, than in group 2, and a significantly higher mortality rate due to thromboembolism in absence of any prophylactic treatment with anticoagulant drugs (10\% of group 1 patients died because of thromboembolism, and $10 \%$ had vascular morbidity). After the introduction of screening of hemostatic parameters and postoperative antithrombotic prophylaxis, morbidity and mortality due to thromboembolic events dropped to 6 and $0.4 \%$, respectively, suggesting the absolute necessity of an adequate anticoagulant prophylactic treatment in these patients to avoid thromboembolic complications [16]. However, prospective randomized trials on the matter are lacking and large prospective studies are needed.

As in patients with obesity, patients with CS are often affected by hyperhomocysteinemia which contributes to the hypercoagulable state seen in these subjects [25].

\section{Conclusions}

Chronic glucocorticoid excess in patients with CS is associated with a hypercoagulability state leading to an increased risk of thromboembolic events.
In line with these data, patients with active CS should be treated as having a prothrombotic disorder and undergo anti-thrombotic prophylaxis during IPS sampling, and special care should be taken in the immediate postoperative period in order to avoid thromboembolic complications.

In the absence of prospective randomized trials, we and other authors suggest the routine use of antithrombotic prophylaxis in patients with CS undergoing transsphenoidal or adrenal surgery, especially in the immediate postoperative period, and the use of heparin during IPS sampling [7, 24, 25]. However, more studies are needed to provide more definite indications about the type (i.e. heparin, low molecular weight heparin, low-dose unfractionated heparin or fondaparinux), intensity and duration of thromboprophylaxis in these patients. Finally, in our opinion, considering the association of many cardiovascular comorbidities in the same patient, antiplatelet therapy could be also considered in all patients with CS.

\section{Disclosure Statement}

The authors declare that no financial or other conflict of interest exists in relation to the content of this article.

\section{References}

1 Cosgriff SW, Diefenbach AF, Vogt W Jr: Hypercoagulability of the blood associated with ACTH and cortisone therapy. Am J Med 1950;9:752-756.

-2 Arnaldi G, Angeli A, Atkinson AB, Bertagna $\mathrm{X}$, Cavagnini F, Chrousos GP, Fava GA, Findling JW, Gaillard RC, Grossman AB, Kola B, Lacroix A, Mancini T, Mantero F, Newell-Price J, Nieman LK, Sonino N, Vance ML, Giustina A, Boscaro M: Diagnosis and complications of Cushing's syndrome: a consensus statement. J Clin Endocrinol Metab 2003;88:5593-5602.

-3 Arnaldi G, Mancini T, Polenta B, Boscaro M: Cardiovascular risk in Cushing's syndrome. Pituitary 2004;7:253-256.

4 Etxabe J, Vazquez JA: Morbidity and mortality in Cushing's disease: an epidemiological approach. Clin Endocrinol (Oxf) 1994;40: 479-484.

5 Brotman DJ, Girod JP, Posch A, Jani JT, Patel JV, Gupta M, Lip GY, Reddy S, Kickler TS: Effects of short-term glucocorticoids on hemostatic factors in healthy volunteers. Thrombosis Res 2006;118:247-252.
6 Fatti LM, Bottasso B, Invitti C, Cavagnini F, Mannucci PM: Markers of activation of coagulation and fibrinolysis in patients with Cushing's syndrome. J Endocrinol Invest 2000;23:145-150.

-7 Van Zaane B, Nur E, Squizzato A, Dekkers OM, Twickler MT, Fliers E, Gerdes VEA, Büller HR, Brandjes DPM: Hypercoagulable state in Cushing's syndrome: a systematic review. J Clin Endocrinol Metab 2009;94: 2743-2750.

8 Franchini M, Lippi G, Manzato F, Vescovi PP, Targher G: Hemostatic abnormalities in endocrine and metabolic disorders. Eur J Endocrinol 2010;162:439-451.

$\checkmark 9$ Sjoberg HE, Blomback M, Granberg PO: Thromboembolic complications, heparin treatment and increase in coagulation factors in Cushing's syndrome. Acta Med Scand 1976;199:95-98

10 Patrassi GM, Dal Bo Zanon R, Boscaro M, Martinelli S, Girolami A: Further studies on the hypercoagulable state of patients with Cushing's syndrome. Thromb Haemost 1985;54:518-520.
11 Dal Bo Zanon R, Fornasiero L, Boscaro M, Cappellato G, Fabris F, Girolami A: Increased factor VIII associated activities in Cushing's syndrome: a probable hypercoagulable state. Thromb Haemostas (Stuttgart) 1982;47:116-117.

12 Casonato A, Pontara E, Boscaro M, Sonino N, Sartorello F, Ferasin S, Girolami A: Abnormalities of von Willebrand factor are also part of the prothrombotic state of Cushing's syndrome. Blood Coagul Fibrinolysis 1999;10:145-151.

13 Patrassi GM, Sartori MT, Viero ML, Scarano L, Boscaro M, Girolami A: The fibrinolytic potential in patients with Cushing's disease: a clue to their hypercoagulable state. Blood Coagul Fibrinolysis 1992;3:789-793.

14 Ambrosi B, Sartorio A, Pizzocaro A, Passini E, Bottasso B, Federici A: Evaluation of haemostatic and fibrinolytic markers in patients with Cushing's syndrome and in patients with adrenal incidentaloma. Exp Clin Endocrinol Diabetes 2000;108:294-298. 
>15 Erem C, Nuhoglu I, Yilmaz M, Kocak M, Demirel A, Ucuncu O, Ersoz O: Blood coagulation and fibrinolysis in patients with Cushing's syndrome: increased plasminogen activator inhibitor-1, decreased tissue factor pathway inhibitor and unchanged thrombin-activatable fibrinolysis inhibitor levels. J Endocrinol Invest 2009;32:169-174.

-16 Boscaro M, Sonino N, Scarda A, Barzon L, Fallo F, Sartori MT, Patrassi GM, Girolami A: Anticoagulant prophylaxis markedly reduces thromboembolic complications in Cushing's syndrome. J Clin Endocrinol Metab 2002;87:3662-3666.

$\checkmark 17$ Daidone V, Pontara E, Romualdi C, Cattini MG, Scaroni C, Albiger N, Pagnan A, Casonato A: Microsatellite (GT) (n) is part of the von Willebrand factor (VWF) promoter region that influences the glucocorticoid-induced increase in VWF in Cushing's syndrome. Thromb Res 2010;125:e275-280.
8 Daidone V, Cattini MG, Pontara E, Sartorello F, Gallinaro L, Marotti A, Scaroni C, Pagnan A, Casonato A: Microsatellite (GT) (n) repeats and SNPs in the von Willebrand factor gene promoter do not influence circulating von Willebrand factor levels under normal conditions. Thromb Haemost 2009;101: 298-304.

19 Casonato A, Daidone V, Sartorello F, Albiger N, Romualdi C, Mantero F, Pagnan A, Scaroni C: Polymorphisms in von Willebrand factor gene promoter influence the glucocorticoid-induced increase in von Willebrand factor: the lesson learned from Cushing syndrome. Br J Haematol 2008;140:230-235.

20 Federici AB, Bader R, Pagani S, Colibretti ML, De Marco L, Mannucci PM: Binding of von Willebrand factor to glycoproteins $\mathrm{Ib}$ and IIb/IIIa complex: affinity is related to multimeric size. Br J Haematol 1989;73:9399.
21 Obuobie K, Davies JS, Ogunko A, Scanlon MF: Venous thrombo-embolism following inferior petrosal sinus sampling in Cushing's disease. J Endocrinol Invest 2000;23:542544.

-22 Rees DA, Hanna FWF, Davies JS, Millis RG, Vafidis J, Scanlon MF: Long-term follow-up results of transsphenoidal surgery for Cushing's disease in a single centre using strict criteria for remission. Clin Endocrinol 2002; 56:541-551.

23 Boscaro M, Arnaldi G: Approach to the patient with possible Cushing's syndrome. J Clin Endocrinol Metab 2009;94:3121-3131.

-24 Fallo F, Sonino N: Should we evaluate for cardiovascular disease in patients with Cushing's syndrome? Clin Endocrinol (Oxf) 2009;71:768-771.

25 Terzolo M, Allasino B, Bosio S, Brusa E, Daffara F, Ventura M, Aroasio E, Sacchetto G, Reimondo G, Angeli A, Camaschella C: Hyperhomocysteinemia in patients with Cushing's syndrome. J Clin Endocrinol Metab 2004;89:3745-3751. 